\title{
September 14 Highlights
}

\section{Thrombin generation after ischemic stroke}

Furie et al. measured serial levels of prothrombin fragment F1.2, a marker of thrombin generation, in 320 patients enrolled in the Warfarin Aspirin Recurrent Stroke Study (WARSS). Mean F1.2 levels did not differ by stroke subtype at baseline, but changes in F1.2 over time did vary by stroke mechanism. F1.2 levels were associated with vascular risk factors and were suppressed by warfarin in a dose-dependent fashion. There was a trend toward a higher risk of recurrent stroke or death as F1.2 levels increased.

see page 777

The accompanying editorial by Gregory del Zoppo reviews the activation of the coagulation cascade to ask, "Can a marker of thrombin generation be used as an indicator of stroke etiology?"- -and can strokes with unassigned etiology be identified by evidence of thrombosis? He further notes that while a causal relationship between cryptogenic stroke and increased PF1.2 levels was not revealed by this study, thrombin may still be important.

see page 768

\section{Hepatitis B vaccine and risk of MS}

In a prospective study of a large European population, Hernán et al. found that the incidence of multiple sclerosis (MS) increased during the 3 years following immunization with the recombinant hepatitis $B$ vaccine.

see page 838

The accompanying editorial by Naismith and Cross notes that this article may reopen the debate about the vaccine causing or contributing to MS. The methods used were sound, and extensive measures were taken to confirm the diagnosis and reduce potential biases. However, the present study stands in contrast to multiple studies and expert panels that have concluded that there is no link between the hepatitis $B$ vaccine and MS. They review possible biases in the study and emphasize the fact that in the Hernán et al. study $93.3 \%$ of those in the study population with MS had never received the hepatitis $B$ vaccine. They conclude that the indisputable benefit that the hepatitis $B$ vaccine provides against an infection that kills 5,000/year in the United States must be weighted against any uncommon risks that remain in dispute.

see page 772

\section{APOE does not influence cognitive decline in pre-clinical AD}

Ohtake et al. screened sporadic and familial DLB patients for mutations in $\alpha$ - and $\beta$-synuclein. They discovered non-conservative amino acid alterations in two unrelated DLB patients in the $\beta$-synuclein gene, suggesting that $\beta$-synuclein may be involved in DLB pathogenesis.

see page 805

The accompanying editorial by Kirk C. Wilhelmsen notes that the approach taken by Ohtake et al. differs from the usual strategy of studying a disease in a family to define linkage, and then a gene mutation. Here they went directly from the observation that mutations in $\alpha$-synuclein can cause familial PD to studying $\beta$-synuclein in a large number of sporadic and familial patients with dementia with Lewy bodies - "a gene resequencing" strategy. The high prior probability that $\beta$-synuclein mutations could cause neurodegeneration greatly increases the confi-dence that Ohtake et al. are correct. While one could argue that if they had sequenced the complete gene for a large number of normal subjects they might have found similar sequence changes in the $\beta$-synuclein gene, this seems unlikely.

see page 770
Bunce et al. show that persons in the pre-clinical phase of Alzheimer disease (AD) exhibited greater global cognitive decline than non-demented adults. Importantly, APOE genotype did not modify the rate of decline in to-be-demented persons, or individuals who would remain free of $\mathrm{AD}$.

see page 816

\section{Elevated Aß42 plasma levels in women with MCI}

Assini et al. detected a significant increase of amyloid- $\beta$ 42 plasma levels in women with amnestic mild cognitive impairment, chosen as early stage of Alzheimer disease. This finding links $\mathrm{A} \beta 42$ accumulation with the postmenopausal drop of estrogens in the pre-clinical phase of the disease. see page 828 


\section{Cutaneous allodynia in migraines}

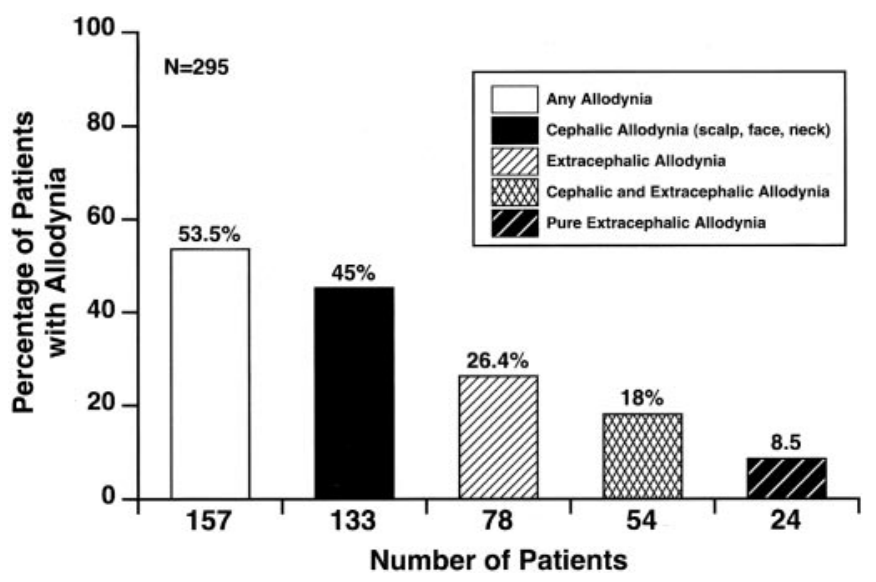

Cutaneous allodynia, a manifestation of central sensitization, has therapeutic implications in migraine including pain-free response, consistency of response, and recurrence. Mathew et al., based on a semistructured questionnaire on 295 migraineurs, identified allodynia in $53.5 \%$, mostly cephalic and some extracephalic. Allodynia correlated with the duration of illness and frequency of attacks.

see page 848

\section{HIV-dementia more frequent in older patients}

Valcour et al. report increased rates of dementia and minor cognitive motor disorder associated with age in the Hawaii Aging With HIV cohort.

see page 822

\section{Chronic daily headache in adolescents and adults}

Bigal et al. showed that among adolescents and adults there were substantial differences in the distribution of chronic daily headache subtypes. In comparison with adults, adolescents had a significantly lower risk of transformed migraine (68.8\% vs $87.4 \%$ ) and medication overuse ( $28.2 \%$ vs $62.5 \%)$. Adolescents may develop the disorder in the absence of medication overuse because they are at increased biological risk.

see page 843

\section{Topiramate in diabetic neuropathy}

Raskin et al. compared the anticonvulsant topiramate to placebo in 323 subjects with moderate to severe painful diabetic neuropathy. After 12 weeks (including monotherapy without rescue analgesia in weeks 7 to 12), topiramate reduced pain and body weight more effectively than placebo, without disrupting glycemic control.

see page 865

\section{Emotional processing in the minimally conscious state}

Laureys et al. report a minimally conscious patient in whom presentation of emotional stimuli induced a near normal cerebral activation as measured by PET and event-related potentials.

see page 916 


\section{Neurology}

September 14 Highlights

Neurology 2004;63;766-767

DOI 10.1212/WNL.63.5.766

This information is current as of September 13, 2004

\section{Updated Information \&}

Services

Permissions \& Licensing

Reprints including high resolution figures, can be found at: http://n.neurology.org/content/63/5/766.full

Information about reproducing this article in parts (figures,tables) or in its entirety can be found online at:

http://www.neurology.org/about/about_the_journal\#permissions

Information about ordering reprints can be found online:

http://n.neurology.org/subscribers/advertise

Neurology ${ }^{\circledR}$ is the official journal of the American Academy of Neurology. Published continuously since 1951, it is now a weekly with 48 issues per year. Copyright. All rights reserved. Print ISSN: 0028-3878. Online ISSN: 1526-632X.

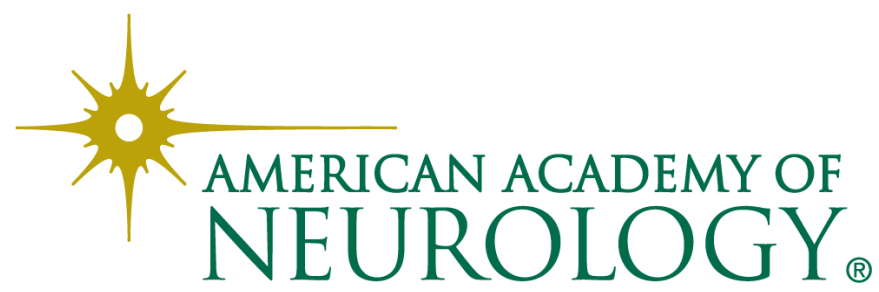

